\title{
COMPETÊNCIA EM INFORMAÇÃO NO ÂMBITO DA COMUNIDADE LGBTQ: UM LEVANTAMENTO DAS PUBLICAÇÕES CIENTÍFICAS NACIONAIS E INTERNACIONAIS
}

\author{
INFORMATION LITERACY IN THE CONTEXT OF LGBT \\ COMMUNITY: A SURVEY OF NATIONAL AND \\ INTERNATIONAL PUBLICATIONS
}

\author{
Selma Leticia Capinzaiki Ottonicara \\ Jean Fernandes Brito ${ }^{b}$ \\ Rafaela Carolina Silvac \\ Everaldo Henrique dos Santos Barbosad \\ Cassia Regina Bassan de Moraese
}

\begin{abstract}
RESUMO
Introdução: A comunidade LGBTQ tem enfrentado dificuldades na sociedade contemporânea devido ao preconceito de alguns indivíduos. Atualmente, as leis de diversos países, bem como as políticas públicas têm sido direcionadas a esses grupos, para incluí-los em sociedade. O foco é garantir o direito aos seres humanos e o respeito às minorias, objetivando melhorar a qualidade de vida dessas pessoas. Perante tais reflexões, o problema de pesquisa buscou refletir as maneiras pelas quais a competência em informação pode contribuir para que a sociedade desenvolva o respeito à comunidade LGBT. Objetivos: O artigo objetiva demonstrar os modos pelos quais a literatura da Ciência da Informação tem tratado a temática, a fim de incluir a comunidade LGBTQ em suas pesquisas. Não obstante, objetiva-se demonstrar como a competência em informação pode contribuir para que a comunidade LGBTQ seja respeitada em sociedade. Metodologia: A metodologia envolve uma revisão sistemática da literatura na área da Ciência da Informação sobre a competência em informação e o movimento
\end{abstract}

a Doutoranda do Programa de Pós-Graduação em Ciência da Informação da Universidade Estadual Paulista Júlio de Mesquita Filho (PPGCI-UNESP). E-mail: selma.leticia@hotmail.com

b Mestrando do Programa de Pós-Graduação em Ciência da Informação da Universidade Federal de Santa Catarina (PPGCI-UFSC). E-mail: jjeanfernandes@gmail.com

c Doutoranda do Programa de Pós-Graduação em Ciência da Informação da Universidade Estadual Paulista Júlio de Mesquita Filho (PPGCI-UNESP). E-mail: rafaelacarolinasilva@gmail.com

d Mestranda do Programa de Pós-Graduação em Ciência da Informação da Universidade Estadual Paulista Júlio de Mesquita Filho (PPGCI-UNESP). E-mail: contato.pitu@hotmail.com

e Professora do Departamento de Ciência da Informação da Faculdade de Filosofia e Ciências da Universidade Estadual Paulista Júlio de Mesquita Filho (UNESP). E-mail:

crbassan@gmail.com 
LGBTQ, a fim de identificar como o tema vem sendo tratado pela área. Resultados: Os temas são trabalhados de maneira tímida pela área, tanto em nível nacional quanto internacional. Além disso, desenvolveu-se um modelo de respeito ao LGBTQ por meio desta competência, a fim de ser aplicado em diversos contextos de modo a reduzir 0 preconceito com estas pessoas. Conclusões: Existe a necessidade de pesquisas mais aprofundadas sobre a temática. $O$ uso da informação eficaz contribui para a compreensão do contexto dos LGBTQ e o respeito ao seu modo de vida.

Descritores: Competência em informação. Comunidade LGBTQ. Respeito à diversidade. Interdisciplinaridade. Revisão Sistemática da Literatura.

\section{INTRODUÇÃO}

O preconceito ocorre quando indivíduos desconhecem por diversas questões, o fenômeno em que estão julgando, como valores ensinados desde a infância, medo do desconhecido, desejo inconsciente em fazer parte do objeto criticado e o desconhecimento histórico das práticas e interpretações.

Geralmente, sofrem rejeição social às minorias que não estão conforme os determinantes culturais da sociedade. Esses determinantes culturais são disseminados pela mídia por um período e acabam confirmando o estereótipo de vida entendido como 'correto ou normal' para as pessoas. Entretanto, o movimento dos direitos humanos vem mudando essas preconcepções e disseminando novos valores culturais, como o respeito à diversidade. Em paralelo aos direitos humanos, surge a área científica como compartilhadora desses ideais ao disseminar as práticas dos grupos. Assim, o conhecimento e a popularização das minorias os tornam mais conhecidos, fazendo com que as pessoas compreendam seus diferentes modos de vida e passem a respeitálos.

Uma dessas minorias é a comunidade de Lésbicas, Gays, Bissexuais e Transexuais (LGBTQ), que tem trazido à discussão da complexidade sexual em sociedade. Ressalta-se que o mundo não é mais dividido entre homens e mulheres heterossexuais, mas em outras variedades de preferências. Além disso, essa comunidade tem trazido mudanças no vestuário das pessoas, democratizando a moda para todos os gostos.

Portanto, não existem roupas de homens ou de mulheres já determinadas, 
não há limites de formas, cores e tecidos. O fundamental é que o indivíduo se sinta bem em utilizar sua criatividade pessoal, respeitando os comportamentos e o modo de se vestir de todos os indivíduos.

Entretanto, devido ao preconceito de alguns indivíduos, a comunidade LGBTQ tem enfrentado dificuldades na sociedade contemporânea. Atualmente, as leis de diversos países, bem como as políticas públicas, têm sido direcionadas a esses grupos, a fim de incluí-los em sociedade. O foco é garantir o direito aos seres humanos e o respeito às minorias, determinando que a população possa melhorar sua qualidade de vida.

$\mathrm{Na}$ área da Ciência da Informação existe uma temática conhecida como competência em informação (Colnfo), que demonstra a importância da aprendizagem ao longo da vida como meio ao exercício à cidadania (BELLUZZO, 2007; SILVA; OTTONICAR; YAFUSHI, 2017). A pessoa competente em informação respeita questões legais e éticas, compreendendo os temas sociais e econômicos sobre o uso da informação (BELLUZZO, 2007; OTTONICAR, 2016; LAU, 2007; BUNDY, 2004).

Além disso, a pessoa que se utiliza da Colnfo avalia o conteúdo do texto e das fontes (BELLUZZO, 2007; BEAL, 2004) por meio das intenções e ideologias por trás de tais fontes (OTTONICAR; FERES, 2014; OTTONICAR, 2016; BELLUZZO; FERES, 2015). Com isso, defende-se que a Colnfo contribui para que o indivíduo aprenda sobre a diversidade da humanidade e da relevância dessas diferenças para compor a sociedade. As pessoas acessam a informação sobre diferentes assuntos e grupos existentes para construir conhecimento sobre a sociedade.

Perante tais reflexões, o objetivo da pesquisa trata sobre as maneiras pelas quais a Colnfo pode contribuir para que a sociedade desenvolva 0 respeito à comunidade LGBTQ. Além disso, a pesquisa tem um segundo objetivo, o de demonstrar como a literatura da Ciência da Informação e áreas correlatas têm tratado a temática, a fim de incluir a comunidade LGBTQ em suas pesquisas.

A pesquisa foi desenvolvida a partir de uma metodologia conceitual conhecida como Revisão Sistemática da Literatura (RSL), baseada no protocolo 
e no formulário de condução, assim como no modo de extração dos dados de cada artigo encontrado. Essa RSL permitiu demonstrar a relevância da temática para o campo da Ciência da Informação, tendo em vista que é uma área do conhecimento propulsora da interdisciplinaridade de temas e do respeito às minorias.

\section{COMPETÊNCIA EM INFORMAÇÃO (COINFO)}

A Colnfo está envolta ao conhecimento e as habilidades adquiridas pelos indivíduos no decorrer de sua existência, como um conjunto de conceitos, práticas, experiências, culturas e vivências. Paradoxalmente, há uma cultura defasada ao domínio da Colnfo, bem como lacunas no entendimento da importância da construção desse conceito para a sociedade. Desse modo, a explanação das bases literárias é fundamental para a representação social, não apenas sobre o que significa o termo, mas também da sua representatividade nas questões éticas e sociais (DUDZIAK, 2003).

Para Dudziak (2003), a Colnfo proporciona um conceito que vai além da soma de suas partes (competência e informação). A informação está presente em toda a sociedade e nas áreas do saber. Já a competência significa promover a interação e a assimilação de princípios conceituais adquiridos. $O$ conhecimento gerado e aplicado com ética e eficiência à sociedade e aos grupos sociais é a caracterização do que constitui essa competência (RIGHETTO, 2018).

A Colnfo é um conjunto complexo de informações transformadas e processadas pelo indivíduo, gerando conhecimento. $O$ processo de conhecimento se concerne por meio de fases inter-relacionadas, conforme se apresenta a seguir no fluxograma da Colnfo: 


\section{Figura 1 - Fluxograma da Competência em Informação}

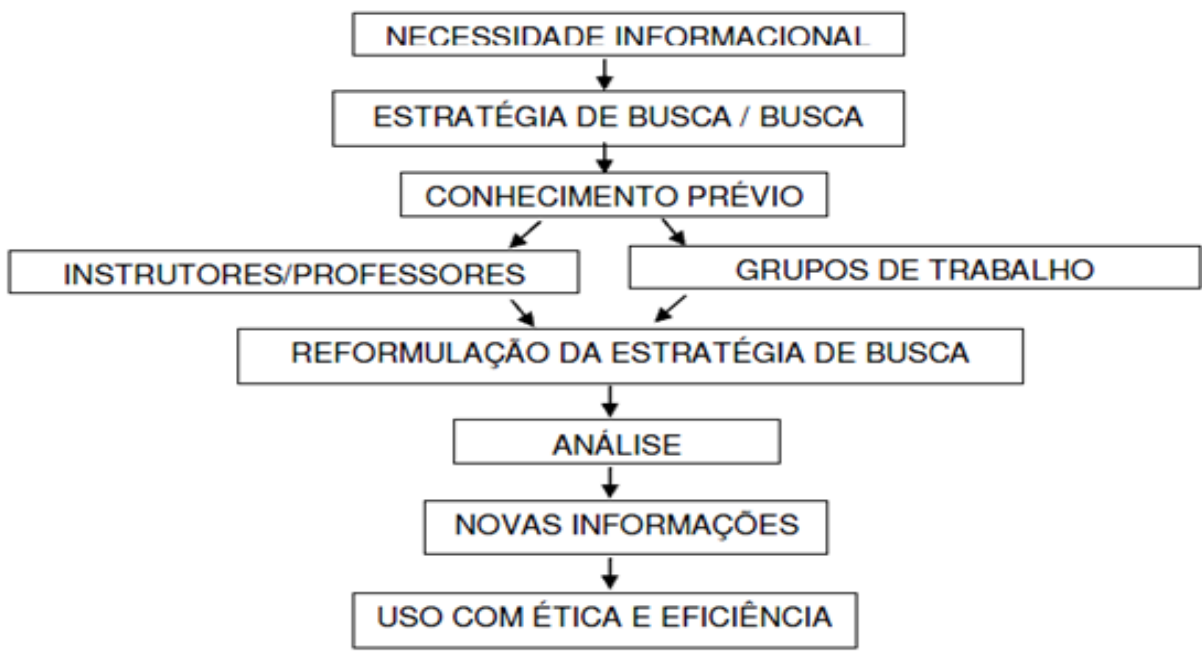

Fonte: Reis, Carvalho e Muniz (2011).

Nesse prisma, o processo cognitivo apresentado na Figura 1 mostra que a sociedade, na atual era da informação, está inserida em um contínuo fluxo de informações disseminadas. Tais informações são compartilhadas nas instituições de ensino, no ambiente de trabalho, nas mídias sociais ou nas relações sociais. Uma real revolução informacional da sociedade contemporânea (REIS; CARVALHO; MUNIZ, 2011). A comunidade LGBTQ, por representar uma minoria, acaba sendo alvo de preconceitos sociais, pelo uso inadequado de informações que não foram processadas e digeridas com ética e eficiência por parte dos opressores.

A disseminação da informação é constante nos meios digitais e a sociedade tem desenvolvido um conhecimento a partir do acesso as informações digitais. Portanto, as informações que permeiam as mídias sociais precisam ser pesquisadas, já que são muito utilizadas pela sociedade atual. Algumas ações desprovidas de bom senso e ética nessas mídias geram sérios ataques homofóbicos à comunidade LGBTQ, levando a muitos casos de mortes no Brasil e ao redor do mundo (SERAFIM; FREIRE, 2012).

Para Serafim e Freire (2012) "A falta de informação ou a disseminação de informações errôneas favorece a ignorância, o preconceito, a aversão e a negação do que é diferente." Assim, pode-se dizer que, por um lado os meios de 
comunicação de massa e os ambientes organizacionais e sociais semeiam atos homofóbicos. Em contrapartida, a Ciência da Informação pode promover e corroborar com a Colnfo dos indivíduos em caráter de responsabilidade social. Tal perspectiva promove ações transformadoras em sociedade como incentivo a princípios éticos e sociais voltados ao respeito a diversidade.

Nesse viés, Santos, Targino e Freire (2017, p. 122) defendem a importância do papel da informação "[...] como elemento de conscientização que pode romper com preconceitos e desigualdades, propiciando espaços de pluralidade na produção de novos conhecimentos, na promoção da cidadania e na segurança dos indivíduos pertencente à comunidade LGBTQ".

A Colnfo é um domínio da Ciência da Informação, o qual se designa como uma habilidade existente na capacidade humana de se apropriar da informação de maneira ética e social (BELLUZZO, 2007). A comunidade LGBTQ está em crescente evidência diante da sociedade, uma vez que seu contexto tem conquistado espaço nas mídias televisivas e sociais, além de instituições de ensino e organizacionais. Portanto, a Colnfo, progressivamente, pode atuar como subsídio para a evolução e compreensão da sociedade quanto a real existência dos direitos, do respeito e da diversidade sexual que devem ser garantidos a essas pessoas perante a sociedade.

Assim, a responsabilidade e a consciência dos formadores de opinião em relação ao uso, apropriação e disseminação da informação representam fortes aspectos influenciadores na construção do conhecimento social. Tal fato indica a importância de se ter consciência do pré-julgamento da comunidade LGBTQ. Essa comunidade está inserida em uma sociedade exclusa do estereótipo dito como "normal". Entretanto, os cidadãos devem cumprir com suas obrigações de forma igualitária. Os indivíduos possuem direito de ir e vir, mas precisam responder pelos seus atos em sociedade.

\section{COMUNIDADE LGBTQ ENQUANTO MOVIMENTO SOCIAL}

As relações homossexuais sempre existiram na história da humanidade. Como destaca Freud, "A homossexualidade foi reconhecida [...] como uma 
corrente afetivo-pulsional e desejante que está presente, de forma explícita ou latente, em todos os seres humanos" (BARBERO, 1999, p. 19).

Nesse sentido, Spencer (1996) destaca que a palavra 'homossexualismo' apareceu pela primeira vez na década de 1890, através de Charles Gilbert Chaddock, que, traduzindo o termo, do original alemão, para o inglês, designou o relacionamento afetivo entre pessoas do mesmo sexo. Tal denominação apresentou um avanço para a época, pois, nas sociedades antigas, esses relacionamentos não eram devidamente nomeados.

A necessidade de distinguir o relacionamento entre pessoas do mesmo sexo e do sexo oposto levou à introdução, por meio de um médico húngaro, no século $\mathrm{XX}$, da diferenciação entre a homossexualidade e a heterossexualidade, no que diz respeito ao impulso sexual ao qual a pessoa se orienta (FERNÁNDEZ-MARTOS; VIDAL, 1985).

Nesse sentido, Pinho (2010, p. 13), aprimorando as ideias de Foucault (1999), destaca que "A homossexualidade, por ser historicamente datada, depende da noção de sexualidade; dessa maneira, a palavra sexo abarca, atualmente, questões relativas à conduta, ao prazer, à anatomia e às funções biológicas" (PINHO, 2010, p. 13). Dentro desse contexto, a sociedade volta-se para a questão das diferenças entre a homossexualidade e a heterossexualidade. O conceito dualista classificatório de homem e mulher, atração sexual normal e anormal passa a ser visto como questões preconceituosas por indivíduos que não aceitam tal mudança (FOULCAULT, 1999).

O preconceito em relação às raças, classes econômicas, ritos religiosos, em especial à homossexualidade, datam de tempos remotos, perdurando até os dias de hoje (ALLAN; BURRIDGE, 2006), já que:

[...] desde o alvorecer das civilizações, os homens encarniçaram-se, não somente em observar a natureza, mas de definir-lhe a ordem e que, muitas vezes, esta pretensa "ordem natural", assim definida, não é outra coisa senão a projeção de nossas próprias ideias morais ou de nossos próprios preconceitos. É o que se produziu com a sexualidade. (DANIEL; BAUDRY, 1977, p. 45).

Isso ocorre porque as opiniões sobre a homossexualidade e a forma como 
integrá-la em sociedade variam de acordo com épocas e lugares. Daniel e Baudry (1977, p. 32-36) relacionam que, dessa maneira, é possível constatar que existem sociedades favoráveis à homossexualidade.

As relações afetivas entre pessoas do mesmo sexo ainda são consideradas crime em 73 países, segundo dados recentes da Associação Internacional de Lésbicas, Gays, Bissexuais e Transgêneros ILG (Internacional, Lesbian, Gay, Bisexual, Trans and Intersex Association), que monitora as leis relacionadas ao tema há 11 anos. É a chamada "homofobia de estado". O número representa $37 \%$ do total de estados membros da ONU (Organização das Nações Unidas).

Sob essa perspectiva de luta contra a homofobia e o preconceito, destacase o movimento LGBTQ. De acordo com Gohn (2008) os movimentos sociais são ações coletivas de caráter sociopolíticos, construídos por atores sociais pertencentes a diferentes classes e camadas sociais. Eles politizam suas demandas e criam um campo político de força social na sociedade civil, sendo que suas ações se estruturam a partir de repertórios criados sobre temas e problemas em situações de conflitos, litígios e disputas. As ações desenvolvem um processo social e político-cultural que cria uma identidade coletiva no movimento, a partir de interesses em comum.

De acordo com Silva e Santos (2015), o início do movimento LGBTQ no Brasil remonta ao final dos anos 70 . Nesse contexto, em duas décadas os movimentos LGBTQ fizeram história no país e tem ganhado espaços significativos nas mídias sociais. Durante esse tempo, esse público tem lutado pela parceria civil entre homossexuais e os direitos da comunidade LGBTQ que é considerada a mais vulnerável em relação à observância de seus direitos humanos.

\section{METODOLOGIA}

Essa pesquisa é de natureza qualitativa, do tipo descritiva e exploratória. A pesquisa foi construída por meio de uma Revisão Sistemática da Literatura sobre os tópicos Colnfo e o público LGBTQ. Essa busca contribuiu para a 
construção de um referencial teórico seletivo e conciso, além de discussões acerca desta temática.

As bases de dados internacionais pesquisadas foram Library and Information Science Abstracts (LISA), Web of Science (WOS) e Scopus. Em âmbito nacional, utilizou-se a Base de Dados em Ciência da Informação (BRAPCI). Ressalta-se que não foram inseridos limites quanto à data de publicação dos textos.

Para se recuperar o maior número de referências possível, as palavraschave foram escritas em inglês, já que as bases de dados utilizadas recuperam, pelo inglês, textos em todos os idiomas indexados nas plataformas. Foi delimitada a busca por textos relacionados às Ciências Sociais e às Ciências Sociais Aplicadas. Ressalta-se que o período de levantamento de dados ocorreu entre julho/agosto de 2018.

Após esse procedimento, foi realizada a leitura, fichamento e análise dos textos, a fim de entender a proposta e objetivos dos trabalhos e, posteriormente, realizar a extração e sistematização das informações principais.

\section{Quadro 1 - Protocolo da Revisão Sistemática da Literatura}

\begin{tabular}{|l|l|}
\hline $\begin{array}{c}\text { Dados do Protocolo da } \\
\text { RSL }\end{array}$ & \multicolumn{1}{|c|}{ Apresentação } \\
\hline Objetivo Geral & Identificar os pontos confluentes entre Coinfo e a comunidade LGBTQ. \\
\hline $\begin{array}{l}\text { Fontes Pesquisadas para } \\
\text { obtenção dos estudos } \\
\text { Primários }\end{array}$ & LISA, WOS, Scopus e BRAPCI. \\
\hline Restrições & $\begin{array}{l}\text { Trabalhos presentes no campo das Ciências Sociais e das Ciências } \\
\text { Sociais Aplicadas. }\end{array}$ \\
\hline $\begin{array}{l}\text { Critérios de Inclusão e e } \\
\text { Exclusão }\end{array}$ & $\begin{array}{l}\text { Inclusão: Trabalhos em inglês, português (Brasil), espanhol e francês } \\
\text { alocados na área da Ciência da Informação e Ciências Sociais } \\
\text { Aplicadas. Trabalhos que possuem alguma aplicação prática dos } \\
\text { padrões e indicadores da Colnfo para a inclusão social do público } \\
\text { LGBTQ. Artigos de revistas, congressos e conferências científicas. } \\
\text { Artigos que abordam algum tipo de literacia (literacy) na comunidade } \\
\text { LGBTQ. Artigos que abordam o papel das bibliotecas para a leitura e } \\
\text { acesso à informação para aprendizagem dos LGBTQ. } \\
\text { Exclusão: Trabalhos que não estão disponíveis completos e/ou que } \\
\text { possuem conteúdos que precisam ser pagos para serem acessados. }\end{array}$ \\
\hline
\end{tabular}


Selma Leticia Capinzaiki Ottonicar, Jean Fernandes Brito, Rafaela Carolina Silva, Everaldo Henrique dos Santos Barbosa, Cassia Regina Bassan de Moraes

Competência em informação no âmbito da comunidade LGBTQ: um levantamento das publicações científicas nacionais e internacionais

\begin{tabular}{|l|l|}
$\begin{array}{l}\text { Dados extraídos dos } \\
\text { Estudos Primários }\end{array}$ & Título, palavras-chave e resumo. \\
\hline Sintetização dos dados & $\begin{array}{l}\text { Os artigos foram usados para definir os parâmetros para o protocolo e } \\
\text { atributos de extração de dados. }\end{array}$ \\
\hline $\begin{array}{l}\text { Palavras Chave de Busca } \\
\text { nas Bases de Dados }\end{array}$ & $\begin{array}{l}\text { 'information literacy" AND "gay"; } \\
\text { 'information science' AND 'lesbian'; } \\
\text { 'information science' AND 'LGBT'; } \\
\text { 'information science' AND 'GLBT'; } \\
\text { 'information literacy' AND 'transgender'; } \\
\text { 'information literacy' AND 'transexual'; } \\
\text { 'information literacy' AND 'bisexual'. }\end{array}$ \\
\hline $\begin{array}{l}\text { Processo de Seleção dos } \\
\text { Estudos Primários }\end{array}$ & $\begin{array}{l}\text { Os artigos selecionados para download cumpriram com os critérios de } \\
\text { inclusão e exclusão descritos acima. }\end{array}$ \\
\hline $\begin{array}{l}\text { Estratégias de Extração } \\
\text { da Informação }\end{array}$ & $\begin{array}{l}\text { Foram construídas expressões de busca com as palavras-chave } \\
\text { mencionadas acima. Após a submissão das expressões nos } \\
\text { mecanismos de busca, foi realizada a leitura do título e palavras-chave } \\
\text { do documento a fim de aplicar os critérios de inclusão e exclusão. } \\
\text { Foram extraídas informações referentes às contribuições práticas da } \\
\text { Competência em Informação e público LGBTQ em diferentes contextos. }\end{array}$ \\
\hline
\end{tabular}

Fonte: Elaborado pelos autores.

$\mathrm{Na}$ BRAPCl, as palavras-chave resultaram da tradução daquelas indicadas no Quadro 1 como "competência em informação", "competência informacional", "LGBTQ", “lésbicas", "gays", “bissexuais", "transexuais" e "homossexuais".

\section{DISCUSSÕES}

Na WOS não foi recuperado nenhum artigo referente à temática. Já na Scopus foram recuperados nove artigos no total, no entanto, apenas cinco foram analisados. Portanto, 22 artigos foram excluídos porque faziam parte dos critérios de exclusão ao serem formados por um compilado de referências e outros possuíam conteúdo pago, conforme mostra o Quadro 2.

\section{Quadro 2 - Artigos coletados pelo título e palavras-chave}

\begin{tabular}{|l|l|}
\hline \multicolumn{1}{|c|}{ Título do Artigo } & \multicolumn{1}{c|}{ Critério de inclusão ou exclusão } \\
\hline $\begin{array}{l}\text { 1) Development of an LGB- } \\
\text { specific health literacy } \\
\text { scale }\end{array}$ & Incluído porque aborda a health literacy no contexto LGBT \\
\hline $\begin{array}{l}\text { 2) "I plan to be a 10": Online } \\
\text { literacy and lesbian, gay, }\end{array}$ & $\begin{array}{l}\text { Incluído porque se trata do acesso e compartilhamento de } \\
\text { informação por meio da online literacy }\end{array}$ \\
\hline
\end{tabular}

Inf. Inf., Londrina, v. 24, n. 1, p. $484-512$, jan./abr. 2019. 
Selma Leticia Capinzaiki Ottonicar, Jean Fernandes Brito, Rafaela Carolina Silva, Everaldo Henrique dos Santos Barbosa, Cassia Regina Bassan de Moraes

Competência em informação no âmbito da comunidade LGBTQ: um levantamento das publicações científicas nacionais e internacionais

\begin{tabular}{|l|l|}
\hline $\begin{array}{l}\text { bisexual, and transgender } \\
\text { students }\end{array}$ & \\
\hline $\begin{array}{l}\text { 3) eHealth literacy and } \\
\text { intervention tailoring impacts } \\
\text { the } \\
\text { acceptability of a HIVISTI } \\
\text { testing intervention and } \\
\text { sexual } \\
\text { decision making among } \\
\text { young gay and bisexual men }\end{array}$ & Excluído porque o conteúdo era pago \\
\hline $\begin{array}{l}\text { 4) Comprehensive for who? } \\
\text { Neoliberal directives in } \\
\text { Australian 'comprehensive' } \\
\text { sexuality education and the } \\
\text { erasure of GLBTIQ identity }\end{array}$ & $\begin{array}{l}\text { Incluído porque trata da relevância desta competência nos } \\
\text { currículos da escola a fim de que os estudantes LGBT } \\
\text { saibam fazer escolhas sexuais saudáveis }\end{array}$ \\
\hline $\begin{array}{l}\text { 5) Diversity: The importance } \\
\text { of access to information and } \\
\text { political literacy }\end{array}$ & Excluído porque é conteúdo pago \\
\hline $\begin{array}{l}\text { 6) Reading and aids literacy } \\
\text { in Allen Barnett's short fiction }\end{array}$ & $\begin{array}{l}\text { Incluído porque aborda a competência em informação de } \\
\text { gays sobre AIDS. }\end{array}$ \\
\hline $\begin{array}{l}\text { 7) Mining the invisible: } \\
\text { Teaching and learning media } \\
\text { and } \\
\text { diversity }\end{array}$ & $\begin{array}{l}\text { Incluído porque trata da competência midiática voltada ao } \\
\text { combate contra o preconceito com gays e lésbicas }\end{array}$ \\
\hline $\begin{array}{l}\text { 8) United Nations and other } \\
\text { international organizations }\end{array}$ & $\begin{array}{l}\text { Excluído porque se trata de um conjunto de documentos e } \\
\text { não de artigos }\end{array}$ \\
\hline $\begin{array}{l}\text { 9) Oppositional Readings, } \\
\text { Mainstream Writings: a } \\
\text { collection of reviews }\end{array}$ & Excluído porque não trata do tema em questão \\
\hline
\end{tabular}

A base de dados LISA apresentou 37 artigos recuperados com base na análise dos títulos e palavras-chave. Desses, apenas sete foram analisados na pesquisa segundo os critérios de inclusão e exclusão, conforme Quadro 3. Nove artigos foram eliminados pois faziam parte do critério de exclusão "trabalhos que não estão disponíveis completos e/ou que possuem conteúdos que precisam ser pagos para serem acessados".

\section{Quadro 3 - Artigos coletados pelo título e palavras-chave}

\begin{tabular}{|l|l|}
\hline \multicolumn{1}{|c|}{ Título do Artigo } & \multicolumn{1}{c|}{ Critério de inclusão ou exclusão } \\
\hline $\begin{array}{l}\text { 1) Coming-Out: Gay Males' } \\
\text { Information Seeking }\end{array}$ & $\begin{array}{l}\text { Incluído porque se trada do diagnostico da necessidade e } \\
\text { do acesso a informação dos homossexuais. }\end{array}$ \\
\hline $\begin{array}{l}\text { 2) Envisioning Information } \\
\text { Literacy Standard 10 }\end{array}$ & $\begin{array}{l}\text { Excluído porque não se relaciona com a temática, trata da } \\
\text { sociedade civil. } \\
\text { 3) Archival News }\end{array}$ \\
\hline $\begin{array}{l}\text { Excluído pois são arquivos de uma revista e não se refere } \\
\text { a um artigo }\end{array}$ \\
\hline $\begin{array}{l}\text { In Introduction: Gender Issues } \\
\text { Services }\end{array}$ & $\begin{array}{l}\text { Excluído porque trata do feminismo e questões que } \\
\text { envolvem as mulheres e não o publico LGBTQ }\end{array}$ \\
\hline $\begin{array}{l}\text { 5) Keeping Up: Personal Staff } \\
\text { Development }\end{array}$ & $\begin{array}{l}\text { Excluído porque se refere a um conjunto de documentos } \\
\text { de uma conferencia }\end{array}$ \\
\hline
\end{tabular}


Selma Leticia Capinzaiki Ottonicar, Jean Fernandes Brito, Rafaela Carolina Silva, Everaldo Henrique dos Santos Barbosa, Cassia Regina Bassan de Moraes

Competência em informação no âmbito da comunidade LGBTQ: um levantamento das publicações científicas nacionais e internacionais

\begin{tabular}{|c|c|}
\hline $\begin{array}{l}\text { 6) From The Sidelines To } \\
\text { Center Stage: Opportunities } \\
\text { To Discover Voice And } \\
\text { Empowerment Through Web } \\
\text { 2.0 And New Media For } \\
\text { LGBTQ Adult Learners }\end{array}$ & $\begin{array}{l}\text { Excluído porque trata da aprendizagem por meio de } \\
\text { podcast de rádio }\end{array}$ \\
\hline $\begin{array}{l}\text { 7) Finding Out: An } \\
\text { Introduction To Lgbt Studies }\end{array}$ & $\begin{array}{l}\text { Excluído porque não tratava sobre a temática inter- } \\
\text { relacionada }\end{array}$ \\
\hline $\begin{array}{l}\text { 8) Creating Inclusive } \\
\text { Communities: Diversity And } \\
\text { The Responses Of Academic } \\
\text { Libraries }\end{array}$ & Excluído porque não estava relacionado com o tema \\
\hline 9) Censorship Online & $\begin{array}{l}\text { Excluído porque trata de uma tecnologia que ajuda gays e } \\
\text { lésbicas aprenderem }\end{array}$ \\
\hline $\begin{array}{l}\text { 10) Progressive LGBTQ } \\
\text { Reference: Coming Out In } \\
\text { The 21st Century }\end{array}$ & $\begin{array}{l}\text { Excluído porque não tratava sobre a temática inter- } \\
\text { relacionada }\end{array}$ \\
\hline $\begin{array}{l}\text { 11) Reading Women: A Book } \\
\text { Club Guide For Women's } \\
\text { Fiction }\end{array}$ & $\begin{array}{l}\text { Excluído porque é a revisão de livro sobre estudos das } \\
\text { mulheres }\end{array}$ \\
\hline $\begin{array}{l}\text { 12) Interactive Aphra: Skyping } \\
\text { Behn Into Your Classroom }\end{array}$ & $\begin{array}{l}\text { Excluído porque trata de ensinar como entrevistar pessoas } \\
\text { aos estudantes }\end{array}$ \\
\hline $\begin{array}{l}\text { 13) New And Noteworthy: } \\
\text { Coming To Terms With } \\
\text { Librarian Stereotypes And } \\
\text { Self-Image }\end{array}$ & $\begin{array}{l}\text { Excluído porque aborda a competência do bibliotecário e } \\
\text { sua imagem ao público }\end{array}$ \\
\hline $\begin{array}{l}\text { 14) } 2014 \text { APSA Teaching And } \\
\text { Learning Conference And } \\
\text { Track Summaries }\end{array}$ & Excluído porque é o sumário de uma conferência \\
\hline $\begin{array}{l}\text { 15) Mapping The Infoscape } \\
\text { Of LIS Courses For } \\
\text { Intersections Of Health- } \\
\text { Gender And Health-Sexual } \\
\text { Orientation Topics }\end{array}$ & $\begin{array}{l}\text { Excluído porque trata da inserção do tema LGBTQ no } \\
\text { currículo de cursos de Ciência da Informação }\end{array}$ \\
\hline 16) Newly Released & $\begin{array}{l}\text { Excluído porque são sumários de uma revista na área de } \\
\text { jornalismo }\end{array}$ \\
\hline $\begin{array}{l}\text { 17) ASAHP } 2014 \text { Annual } \\
\text { Conference: Abstracts Of The } \\
\text { Presentations }\end{array}$ & Excluído porque é o sumário de uma conferência \\
\hline $\begin{array}{l}\text { 18) Twenty-Plus Years Of } \\
\text { Exclusion In The Boy Scouts } \\
\text { Of America: A Simulated } \\
\text { Debate On Inclusion In } \\
\text { Public And Private Recreation } \\
\text { Agencies }\end{array}$ & $\begin{array}{l}\text { Excluído pois aponta a aplicação de cursos voltados a } \\
\text { diversidade para atletas aceitam os gays mas não aponta a } \\
\text { Colnfo }\end{array}$ \\
\hline $\begin{array}{l}\text { 19) La Experiencia De } \\
\text { Elaborar Infografías } \\
\text { Didácticas Sobre Diversidad } \\
\text { Sexual/ An Experience Of } \\
\text { Elaborating Didactic } \\
\text { Infographics On Sexual } \\
\text { Diversity }\end{array}$ & $\begin{array}{l}\text { Excluído porque trata sobre infográficos na aprendizagem } \\
\text { sobre assuntos como diversidade sexual }\end{array}$ \\
\hline $\begin{array}{l}\text { 20) Japanese Cartoons, } \\
\text { Virtual Child Pornography, } \\
\text { Academic Libraries, And The } \\
\text { Law }\end{array}$ & Excluído porque não trata da temática em questão \\
\hline
\end{tabular}

Inf. Inf., Londrina, v. 24, n. 1, p. 484 - 512, jan./abr. 2019. 
Selma Leticia Capinzaiki Ottonicar, Jean Fernandes Brito, Rafaela Carolina Silva, Everaldo Henrique dos Santos Barbosa, Cassia Regina Bassan de Moraes

Competência em informação no âmbito da comunidade LGBTQ: um levantamento das publicações científicas nacionais e internacionais

\begin{tabular}{|c|c|}
\hline $\begin{array}{l}\text { 21) An Analysis Of } \\
\text { Cyberbullying Among Sexual } \\
\text { Minority University Students }\end{array}$ & Excluído porque não trata da temática em questão \\
\hline $\begin{array}{l}\text { 22) Assessing Safe Spaces } \\
\text { For Digital Scholarship In The } \\
\text { Library }\end{array}$ & Excluído porque não trata da temática em questão \\
\hline $\begin{array}{l}\text { 23) LGBT Literature Courses } \\
\text { And Questions Of Canonicity }\end{array}$ & Excluído porque não trata da temática em questão \\
\hline $\begin{array}{l}\text { 24) Addressing Psychosocial } \\
\text { Factors With Library } \\
\text { Mentoring }\end{array}$ & Excluído porque não trata da temática em questão \\
\hline $\begin{array}{l}\text { 25) Passion Is Not Enough: } \\
\text { Preparing Middle Level } \\
\text { Preservice Teachers To Be } \\
\text { Advocates For Change. }\end{array}$ & Excluído porque não trata da temática em questão \\
\hline $\begin{array}{l}\text { 26) Mixed Message Media: } \\
\text { Girls' Voices And Civic } \\
\text { Engagement In Student } \\
\text { Journalism }\end{array}$ & Excluído porque não trata da temática em questão \\
\hline 27) Conference Catch-Up & Excluído por se tratar de detalhes de uma conferencia \\
\hline $\begin{array}{l}\text { 28) Creating Space For } \\
\text { Agency }\end{array}$ & $\begin{array}{l}\text { Excluído, pois explica o papel da biblioteca disponibilizando } \\
\text { material LBGTQ para os estudantes e orientá-los }\end{array}$ \\
\hline $\begin{array}{l}\text { 29) Improving The Visibility Of } \\
\text { Library Resources Via } \\
\text { Mapping Library Subject } \\
\text { Headings To Wikipedia } \\
\text { Articles }\end{array}$ & Excluído porque não trata da temática em questão \\
\hline $\begin{array}{l}\text { 30) Race And Ethnicity In } \\
\text { Classification Systems: } \\
\text { Teaching Knowledge } \\
\text { Organization From A Social } \\
\text { Justice } \\
\text { Perspective }\end{array}$ & Excluído porque não trata da temática em questão \\
\hline $\begin{array}{l}\text { 31) Lida 2018: Exploring } \\
\text { Underserved Communities }\end{array}$ & Excluído porque não trata da temática em questão \\
\hline $\begin{array}{l}\text { 32) Equitable access: } \\
\text { Information seeking behavior, } \\
\text { information needs, and } \\
\text { necessary library } \\
\text { accommodations for } \\
\text { transgender patrons }\end{array}$ & $\begin{array}{l}\text { Incluído porque trata da importância do acolhimento da } \\
\text { biblioteca para os transexuais e com isso, aprenderem ao } \\
\text { longo da vida. }\end{array}$ \\
\hline $\begin{array}{l}\text { 33) Expanding LIS education } \\
\text { in the US department of } \\
\text { state's diplomacy lab } \\
\text { program: GIS and LGBTI } \\
\text { advocacy in Africa and Latin } \\
\text { America }\end{array}$ & $\begin{array}{l}\text { Incluído porque trata da competência no desenvolvimento } \\
\text { de sistemas de informação para o público LGBTQ. }\end{array}$ \\
\hline $\begin{array}{l}\text { 34) "People Aren't Afraid } \\
\text { Anymore, But It's Hard to Find } \\
\text { Books": Reading Practices } \\
\text { That Inform the Personal and } \\
\text { Social Identities of Self- } \\
\text { Identified Lesbian and Queer } \\
\text { Young Women }\end{array}$ & $\begin{array}{l}\text { Incluído pois trata da leitura voluntária de jovens e sua } \\
\text { aprendizagem. }\end{array}$ \\
\hline
\end{tabular}

Inf. Inf., Londrina, v. 24, n. 1, p. $484-512$, jan./abr. 2019. 
Selma Leticia Capinzaiki Ottonicar, Jean Fernandes Brito, Rafaela Carolina Silva, Everaldo Henrique dos Santos Barbosa, Cassia Regina Bassan de Moraes

Competência em informação no âmbito da comunidade LGBTQ: um levantamento das publicações científicas nacionais e internacionais

\begin{tabular}{|l|l|}
\hline $\begin{array}{l}\text { 35) Places for all? Cape } \\
\text { Town's public library services } \\
\text { to gays and lesbians }\end{array}$ & $\begin{array}{l}\text { Incluído porque fala sobre a escassez dos serviços de } \\
\text { informação para gays e lésbicas }\end{array}$ \\
\hline 36) Lesbian Archive & $\begin{array}{l}\text { Incluído: trata do compartilhamento de informação sobre as } \\
\text { lésbicas }\end{array}$ \\
\hline $\begin{array}{l}\text { 37) Key factors in the } \\
\text { acceptability of treatment as } \\
\text { prevention (TasP) in Scotland: } \\
\begin{array}{l}\text { a qualitative study with } \\
\text { communities affected by HIV }\end{array}\end{array}$ & $\begin{array}{l}\text { Incluído trata da competência em informação sobre o } \\
\text { tratamento para prevenir doenças sexualmente } \\
\text { transmissiveis. }\end{array}$ \\
\hline
\end{tabular}

Fonte: Elaborado pelos autores.

O artigo "I plan to be a 10": Online Literacy and Lesbian, Gay, Bisexual, and Transgender Students foi escrito por Randal Woodland (1999) e publicado pela revista Computers and Composition. Este artigo teve como foco verifica como os LGBT usam as informações online para aprender sobre a comunidade. Um questionário foi aplicado com 75 usuários da internet para verificar como eles compartilham suas experiencias. Os usuários se utilizam da web para obter informação e se expressar sobre as questões LGBT. A habilidade de disseminar as informações online foi denominada como online literacy (WOODLAND, 1999).

$O$ título do terceiro artigo é Development of an LGB-specific health literacy scale publicado na revista Health communication, cujo objetivo é o de discutir a relevância da competência em informação em saúde para reduzir as disparidades que os indivíduos sofrem em relação a saúde sexual. Assim o estudo descreveu características psicométricas com a escala da health literacy. $O$ estudo demonstrou que ainda existem poucas pesquisas sobre o tema e que os LGBT mais velhos possuem pouca informação sobre saúde enquanto os mais jovens demonstraram maiores níveis dessas competências. Uma possível explicação seria o fato de que os mais jovens possuem competência em computação (computer literacy) (ELIASON; ROBINSON; BALSAM, 2018).

Shannon (2016) publicou o artigo Comprehensive for who? Neoliberal directives in Australian 'comprehensive' sexuality education and the erasure of GLBTIQ identity publicado pela Sex Education em 2016. O artigo discute como a educação a sexual atual deve possuir um norteador neoliberal, a fim de incluir o grupo LGBTQ. O foco do artigo é criticar a abordagem utilizado pelos EUA direcionada ao relacionamento heterossexual e a abstinência do sexo. Tal abordagem tem influenciado o contexto da educação sexual da Austrália. Assim, 
o autor sugere inserir a critical literacy (competência em informação crítica) para que os estudantes possam compreender os relacionamentos hetero, homen, mulher, trangênero, com necessidades especiais e idosos a fim de vencer as desigualdades sociais (SHANNON, 2016).

O artigo de Judah Hammer (2003) realizou entrevistas com jovens que se consideram homossexuais de New Brunswick (Nova Jersey) dos Estados Unidos. O título do artigo é Coming-Out: Gay Males' Information Seeking. O objetivo foi diagnosticar se jovens relacionaram suas necessidades de informação, atividades de busca de informações e as condições dessas atividades. Os resultados apontaram que os jovens homossexuais têm necessidade de informação sobre a identidade gay. Já a busca de informação acontecia online com outros gays que experienciaram a mesma situação. Hammer (2003) relatou que houve um período que os indivíduos não buscaram a informação por medo e para ocultar suas necessidades.

Linda Holtzman também contribuiu com a área dos LGBTQ por meio da publicação do artigo Mining the Invisible: teaching and learning media and diversity publicado pela American Behavioral Scientist em 2004. A autora aponta que a mídia é a principal fonte de disseminação de estereótipo e desinformação sobre os homossexuais e isso reforça o preconceito em sociedade. A autora (2004) conclui que os professores podem se utilizar da competência midiática e informação como ferramenta do currículo. Essa competência possibilidade o desenvolvimento do pensamento crítico para que os estudantes valorizem as diferenças.

Os autores Drake e Bielefield, (2017) em o Equitable access: Information seeking behavior, information needs, and necessary library accommodations for transgender patrons destacam as acomodacões exclusivas para acolher usuários transexuais. Pesquisas mostram que pessoas transgêneras têm necessidades únicas que diferem de lésbicas, gays, bissexuais e queer (LGBQ), e experimentam barreiras substanciais para obter serviços de biblioteca de qualidade.

Em Expanding LIS education in the US department of state's diplomacy lab program: GIS and LGBTI advocacy in Africa and Latin America, os autores 
Mehra et al. (2018) apresentam e enfocam dois projetos colaborativos selecionados pelo Howard H. e Baker Jr. Centro de Políticas Públicas da Universidade do Tennessee para se associar ao Departamento de Programa do Laboratório de Diplomacia do Estado. Tal projeto envolve estudantes universitários e professores para estudar política externa e seus desafios. Os projetos permitiram que estudantes de graduação em ciência da informação aprendessem sobre o processo de desenvolvimento de sistemas de informação para lésbicas, gays, advocacia bissexual, transgênero e intersexual. O documento identifica oportunidades, desafios e melhores práticas em entrega de conteúdo, desenvolvimento de recursos e ampliação de relacionamento. $O$ estudo foca no ensino, pesquisa e intersecção entre Advocacia e Ciência da Informação.

O autor Rothbauer (2004) publicou o artigo "People Aren't Afraid Anymore, But It's Hard to Find Books": Reading Practices That Inform the Personal and Social Identities of Self-Identified Lesbian and Queer Young Women baseado em partes de sua dissertação. $O$ trabalho explora as práticas associadas à leitura voluntária na vida de mulheres jovens, cuja identidade sexual foi redescoberta. A pesquisa buscou encontrar diversos atributos como emprestar, comprar e compartilhar sobre textos, especialmente aquelas que se consideram do gênero lésbicas.

Os autores Hart e Mfazo (2010) publicaram Places for all? Cape Town's public library services to gays and lesbians. $\mathrm{O}$ artigo relata uma investigação sobre o fornecimento de literatura gay e lésbica e de serviços de informação para gays e lésbicas em bibliotecas públicas da Cidade do Cabo. Embora, por definição, as bibliotecas públicas sirvam a todos os membros de uma comunidade, a literatura internacional sugere que elas negligenciam as necessidades e interesses de leitura e informação de gays e lésbicas. Assim, ainda que a maioria concorde que os direitos LGBT à informação e serviços iguais são direitos humanos, apenas $55 \%$ consideram pessoas LGBT em seus procedimentos de seleção e muito pouco material é adquirido. Os serviços de informação são escassos, por exemplo, com apenas 10\% das bibliotecas da pesquisa fornecendo informações relacionadas a LGBT em seus arquivos de 
informações da comunidade.

Juhasz e Ma (2011) apresentam uma pesquisa denominada Lesbian Archives, publicada pela GLQ com o intuito de mostrar a realidade vivida pela comunidade lésbica no passado. As autoras (2011) realizaram uma busca profunda de arquivos midiáticos que retratam os objetos e práticas antigas para compará-las com as atuais. A pesquisa realizada introduz uma série de artigos sobre artistas, acadêmicos, ativistas e arquivistas lésbicas, usando uma variedade de métodos e vernáculos para compartilhar e preservar cultura lésbica. Essas informações apresentam impacto relevante para a comunidade LGBTQ.

Young, Flowers e McDaid (2015) publicaram uma pesquisa na Escócia pela revista Sexual Transmitted Infections. O artigo teve como título Key factors in the acceptability of treatment as prevention (TasP) in Scotland: a qualitative study with communities affected by HIV. Os resultados da pesquisa evidenciaram a necessidade de entender os fatores que podem prevenir ou facilitar o uso efetivo do tratamento do HIV como prevenção dessas doenças em nível individual. Com isso, relata as descobertas do primeiro estudo qualitativo no Reino Unido que explorou a aceitabilidade do tratamento como prevenção entre homossexuais, bissexuais nas comunidades africanas migrantes na Escócia. A pesquisa mostrou as desigualdades na competência em informação sobre 0 Vírus da Imunodeficiência Humana (HIV), podendo ser uma séria barreira ao tratamento. Além disso, a pesquisa apontou fatores que colocam os indivíduos em risco, tais como restrições sociais, criminalização da transmissão, aumento do risco de infecção sexualmente transmissível e aumento da carga de tratamento.

Lee (2013) publicou o artigo Reading and AIDS literacy in Allen Barnett's short fiction. $\mathrm{O}$ autor realizou um levantamento de textos que retratam assuntos sobre o impacto da competência em informação dos gays sobre a AIDS. O autor (2013) apresentou conceitos práticos sobre a aprendizagem da doença no que se refere às práticas de leitura e troca de informações. Lee (2013) na pesquisa as histórias de Allen Barnett e as recentes discussões públicas em torno da morte do ex-prefeito de Nova York, Ed Koch, argumentando o cultivo da 
alfabetização sobre a AIDS como uma prática e competência fundamental para desvendar lacunas e tabus sobre a AIDS. É importante ressaltar que nos últimos anos o índice de vulnerabilidade de doenças sexualmente transmissíveis tem aumentado de maneira significativa e coloca em riscos os indivíduos que apresentam dificuldades em relação à Colnfo.

$\mathrm{Na}$ base de dados brasileira BRAPCl, a busca de dados foi realizada a partir de duas buscas separadas sobre os termos "competência em informação", "LGBTQ", "lésbicas", "gays", "bissexuais", "transexuais" e "homossexuais". Apesar da busca ter ocorrido de maneira separada, escolheram-se os textos que tratavam de ambos os temas.

O termo "competência em informação" gerou um total de 703 artigos científicos publicados na área da Ciência da Informação entre 1972 e 2018 no Brasil. Os artigos estavam conectados com temáticas e contextos diversos como a educação, bibliotecas, empresas, entre outros.

Pesquisou-se também os termos LGBTQ, Gays, Lésbicas, Homossexuais, Bissexuais e Transexuais, totalizando 753 artigos. Entretanto, nenhum dos artigos encontrados estavam inter-relacionados com o tema da Colnfo. Esse fato demonstra a necessidade de estudos na área da Ciência da Informação no Brasil.

A Colnfo tem potencial de contribuição com a redução do preconceito contra as minorias, como é o caso da comunidade LGBTQ. Essa contribuição acontece à medida que os indivíduos desenvolvem capacidades para interpretar e aprender a partir da informação disponível do contexto em sociedade.

Alguns artigos coletados tratam da questão da Colnfo no contexto da saúde dessa comunidade, tendo em vista o combate às doenças sexualmente transmissíveis. Esse tipo de abordagem pode ser desenvolvido por meio de políticas públicas de incentivo à proteção tanto da comunidade LGBTQ quanto da sociedade.

As políticas públicas também podem atuar na disseminação de informação de saúde e para que a sociedade aprenda a compreender a comunidade LGBTQ. Essas políticas podem contribuir para o combate ao preconceito de que homossexuais, por exemplo, são pessoas que possuem um 
Selma Leticia Capinzaiki Ottonicar, Jean Fernandes Brito, Rafaela Carolina Silva, Everaldo Henrique dos Santos Barbosa, Cassia Regina Bassan de Moraes

Competência em informação no âmbito da comunidade LGBTQ: um levantamento das publicações científicas nacionais e internacionais

risco mais alto de contrair doenças sexualmente transmissíveis, ao serem comparados com heterossexuais.

Os cursos de educação básica podem aproveitar a Colnfo no desenvolvimento das atividades sobre as diferenças e o convívio em sociedade. Essa competência possui padrões e indicadores que tem sido reconhecido como fundamentais para nortear a implementação da Colnfo na prática, principalmente no continente americano.

Tais padrões são disseminados em documentos internacionais por órgãos como a Association of College and Research Libraries (ACRL) e International Federation of Library Associations (IFLA), por exemplo. Belluzzo (2007) adaptou e traduziu tais padrões e indicadores ao contexto brasileiro. Por isso, tais elementos foram utilizados como norteadores do respeito à comunidade LGBTQ.

\section{Quadro 4 - Padrões e indicadores de Colnfo}

\begin{tabular}{|c|c|}
\hline Padrão & Indicadores \\
\hline $\begin{array}{l}\text { Padrão } 1 \text { - A pessoa competente em } \\
\text { informação determina a natureza e a } \\
\text { extensão da necessidade de informação. }\end{array}$ & $\begin{array}{l}\text { Define e reconhece a necessidade de } \\
\text { informação } \\
\text { Identifica uma variedade de tipos e formatos } \\
\text { de fontes de informação potenciais }\end{array}$ \\
\hline $\begin{array}{l}\text { Padrão } 2 \text { - A pessoa competente em } \\
\text { informação acessa a informação necessária } \\
\text { com efetividade. }\end{array}$ & $\begin{array}{l}\text { Considera os custos e benefícios da } \\
\text { aquisição da informação necessária } \\
\text { Seleciona os métodos mais apropriados de } \\
\text { busca e/ou sistemas de recuperação da } \\
\text { informação para acessar a informação } \\
\text { necessária. } \\
\text { Constrói e implementa estratégias de busca } \\
\text { delineadas com efetividade } \\
\text { Busca a informação via eletrônica ou com } \\
\text { pessoas utilizando uma variedade de } \\
\text { métodos } \\
\text { A pessoa competente em informação } \\
\text { retrabalha e melhora a estratégia de busca } \\
\text { quando necessário } \\
\text { A pessoa competente em informação extrai, } \\
\text { registra e gerencia a informação e suas } \\
\text { fontes. }\end{array}$ \\
\hline $\begin{array}{l}\text { Padrão } 3 \text { - A pessoa competente em } \\
\text { informação avalia criticamente a informação e } \\
\text { as suas fontes. } \\
\text { Padrão } 4 \text { - A pessoa competente em } \\
\text { informação, individualmente ou como } \\
\text { membro de um grupo, usa a informação com } \\
\text { efetividade para alcançar um objetivo/obter } \\
\text { um resultado. }\end{array}$ & $\begin{array}{l}\text { Demonstra conhecimento da maior parte das } \\
\text { ideias da informação obtida } \\
\text { Articula e aplica critérios de avaliação para a } \\
\text { informação e as fontes } \\
\text { Compara o novo conhecimento com o } \\
\text { conhecimento anterior para determinar o } \\
\text { valor agregado, contradições ou outra } \\
\text { característica da informação } \\
\text { É capaz de sintetizar a informação para } \\
\text { desenvolver ou completar um projeto }\end{array}$ \\
\hline
\end{tabular}




\begin{tabular}{|c|c|}
\hline & $\begin{array}{l}\text { Comunica os resultados do projeto com } \\
\text { efetividade }\end{array}$ \\
\hline $\begin{array}{l}\text { Padrão } 5 \text { - A pessoa competente em } \\
\text { informação compreende as questões } \\
\text { econômicas, legais e sociais da ambiência do } \\
\text { uso da informação e acessa e usa a } \\
\text { informação ética e legalmente. }\end{array}$ & $\begin{array}{l}\text { Demonstra compreensão sobre as questões } \\
\text { legais, éticas e socioeconômicas que } \\
\text { envolvem a informação, a comunicação e a } \\
\text { tecnologia } \\
\text { Cumpre as leis, regulamentos, políticas } \\
\text { institucionais e normas relacionadas ao } \\
\text { acesso e uso às fontes de informação } \\
\text { Indica as fontes de informação nas } \\
\text { comunicações do produto ou resultados }\end{array}$ \\
\hline
\end{tabular}

Fonte: Belluzzo (2007).

Os padrões elaborados por Belluzzo (2007) são baseados em cinco dimensões, a percepção da necessidade, o acesso, a avaliação, uso da informação e compreensão das questões éticas e legais. Cada um dos padrões possui indicadores, ou seja, ações cognitivas e comportamentais que contribuem para que os indivíduos atuem em sociedade.

$O$ acesso à informação se refere à busca de dados em diversas fontes sobre determinado assunto. A pessoa precisa perceber qual a informação necessária e quais os locais ideais para se iniciar a busca (BELLUZZO, 2007). $\mathrm{O}$ acesso à informação acontece por meio das tecnologias de informação e comunicação e das tecnologias analógicas, tais como livros, documentos e relatórios.

Posteriormente, é fundamental avaliar essas informações em relação ao seu conteúdo e a fonte (BEAL, 2004). Existem intenções que acompanham os textos, pois são escritos por pessoas provenientes de uma cultura e ideologia de pensamento. O desafio da pessoa competente em informação é buscar informações sobre as fontes e as intenções de compartilhar a informação.

O uso da informação é o objetivo final do acesso à informação e pode se traduzir na resolução de um problema, tomada de decisão, inovação, construção de conhecimento (OTTONICAR, 2016) como também na conscientização social sobre a importância da aceitação da comunidade LGBTQ. Após o uso, a pessoa pode compartilhar o conhecimento construído com os demais para que os cidadãos aprendam e pratiquem o respeito às pessoas.

A fim de contribuir com a disseminação da comunidade LGBTQ e o respeito a diversidade, os padrões podem estar voltados à essas pessoas. $O$ foco é que a sociedade tenha mais contato com indivíduos diferentes, 
aprendendo a conviver e ter o direito de escolha. Essas ideias são representadas pelo Quadro 5, conforme segue.

\section{Quadro 5 - Padrões de Colnfo voltados ao respeito da comunidade LGBTQ}

\begin{tabular}{|c|c|}
\hline Padrões e Indicadores de Colnfo & Contexto da comunidade LGBTQ \\
\hline $\begin{array}{l}\text { Padrão } 1 \text { - A pessoa competente em } \\
\text { informação determina a natureza e a } \\
\text { extensão da necessidade de informação. } \\
\text { Padrão } 2 \text { - A pessoa competente em } \\
\text { informação acessa a informação necessária } \\
\text { com efetividade. }\end{array}$ & $\begin{array}{l}\text { 1. Definição e articulação da necessidade } \\
\text { de informação } \\
\text { A pessoa que respeita a diversidade percebe } \\
\text { que necessita mais informação sobre a } \\
\text { comunidade LGBTQ para conhecer mais o } \\
\text { seu contexto. Reconhece a necessidade de } \\
\text { aprender e por isso decide fazer algo para } \\
\text { encontrar a informação. Expressa essa } \\
\text { necessidade de informação para outras } \\
\text { pessoas e começa o processo de busca da } \\
\text { informação. } \\
\text { 2. Localização da informação } \\
\text { A pessoa que respeita a diversidade identifica } \\
\text { e avalia as fontes potenciais sobre a } \\
\text { comunidade LGBTQ, desenvolve as } \\
\text { estratégias de busca, acessa fonte de } \\
\text { informação previamente selecionada e } \\
\text { seleciona e recupera a informação em uma } \\
\text { variedade de formatos. }\end{array}$ \\
\hline $\begin{array}{l}\text { Padrão } 3 \text { - A pessoa competente em } \\
\text { informação avalia criticamente a informação } \\
\text { e as suas fontes. } \\
\text { Padrão } 4 \text { - A pessoa competente em } \\
\text { informação, individualmente ou como } \\
\text { membro de um grupo, usa a informação com } \\
\text { efetividade para alcançar um objetivo/obter } \\
\text { um resultado. }\end{array}$ & $\begin{array}{l}\text { 1. Acesso à informação } \\
\text { A pessoa que respeita a diversidade analisa, } \\
\text { examina e extraí a informação sobre o } \\
\text { contexto LGBTQ, interpreta a informação, } \\
\text { seleciona e sintetiza a informaçãa, avalia a } \\
\text { relevância da informação obtida. } \\
\text { 2. Organização da informação } \\
\text { Organiza e aplica categorias para a } \\
\text { informação, agrupa a informação obtida, } \\
\text { determina qual é a melhor informação e a mais } \\
\text { útil para suprir sua necessidade. }\end{array}$ \\
\hline $\begin{array}{l}\text { Padrão } \mathbf{5} \text { - A pessoa competente em } \\
\text { informação compreende as questões } \\
\text { econômicas, legais e sociais da ambiência do } \\
\text { uso da informação e acessa e usa a } \\
\text { informação ética e legalmente. }\end{array}$ & $\begin{array}{l}\text { 1. Uso da informação } \\
\text { Busca novas maneiras de comunicar, } \\
\text { apresentar e usar a informação sobre o modo } \\
\text { de vida LGBTQ e seu contexto, aplica a } \\
\text { informação coletada na prática e na teoria, } \\
\text { aprende e internaliza a informação como } \\
\text { forma de conhecimento pessoal, e pode } \\
\text { apresentar a informação como um produto. } \\
\text { 2. Comunicação e uso ético da informação } \\
\text { Compreende o uso ético da informação sobre } \\
\text { a comunidade LGBTQ, respeita o uso legal da } \\
\text { informação, dissemina o conhecimento com }\end{array}$ \\
\hline
\end{tabular}




\begin{tabular}{|l|l|}
\hline & $\begin{array}{l}\text { propriedade intelectual, usa o conhecimento } \\
\text { em uma variedade de atividades. }\end{array}$ \\
\hline
\end{tabular}

Fonte: Elaborado pelos autores com base em Belluzzo (2007) e Lau (2007).

Para que o indivíduo respeite a diversidade é preciso aprender e entrar em contato com informações sobre o grupo ou minoria. Por isso, o indivíduo deve perceber sua necessidade de informação (BELLUZZO, 2007; LAU, 2007). Nesse caso, a necessidade está atrelada às informações sobre a comunidade LGBTQ, pois deste modo pode aprender sobre o modo de vida destas pessoas. Posteriormente ao diagnóstico da necessidade emerge a ação para que encontre informação. Então, inicia o processo de busca em sites, redes sociais, notícias e pessoas para verificar os desafios que os LGBTQ encontram na sociedade atual.

Além disso, durante a aprendizagem, o indivíduo deve identificar e avaliar as fontes de informação potenciais (BELLUZZO, 2007; LAU, 2007; BUNDY, 2004). Por isso, a pessoa deve desenvolver estratégias de busca para acessar as fontes de informações consideradas de qualidade no assunto. Nesse momento, a busca ocorre em uma variedade de formatos e suportes.

É fundamental destacar que o indivíduo deve analisar, examinar e extrair a informação (BELLUZZO, 2007; LAU, 2007; BUNDY, 2004) sobre o contexto LGBTQ. Essa atividade é crucial para a construção do conhecimento, pois precisam lidar com desinformação e fake news disponíveis, principalmente aquelas difundidas pelas mídias sociais. O objetivo é verificar o que os veículos de comunicação disseminam sobre essas pessoas e sua importância para o respeito a diversidade e direitos humanos.

Depois da análise, o indivíduo precisa aprender a disseminar as informações de maneira inteligente (BELLUZZO, 2007; LAU, 2007; BUNDY, 2004), isto é, de maneira crítica com base em dados reais sobre o grupo dos LGBTQ. Essa disseminação pode ocorrer por meio das mídias socias, da internet e do processo de socialização. A informação é apresentada como um produto e a intenção é disseminar informações positivas que demonstram ações voltadas a aceitação e valorização da comunidade LGBTQ em sociedade.

Depois de perceber a necessidade, acessar, avaliar e usar a informação, 
os padrões indicam que a pessoa competente em informação deve compreender o uso ético da informação sobre a comunidade LGBTQ. Não obstante, deve respeitar as regras de compartilhamento de informação (BELLUZZO, 2007; LAU, 2007; BUNDY, 2004). A partir de tais reflexões desenvolveu-se um modelo teórico que representa o conhecimento construído por meio do acesso, avaliação e uso da informação voltado ao respeito à essa comunidade, conforme a figura 2.

\section{Figura 2 - Respeito a comunidade LGBT por meio da Colnfo}

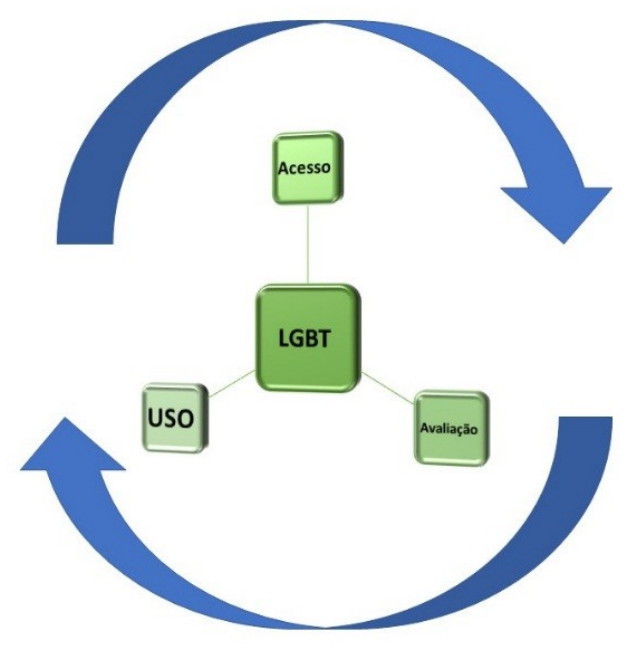

Fonte: Elaborado pelos autores (2018).

A Figura 2 demonstrou que o respeito à comunidade LGBTQ está no centro do modelo conceitual. Esse modelo inter-relaciona os padrões e as etapas de construção da Colnfo para a redução do preconceito. O acesso, avaliação e o uso à informação são pilares inerentes à comunidade, a fim de que os indivíduos saibam como satisfazer suas necessidades informacionais para compreender o modo de vida dessa comunidade.

As setas representam o processo de uso da informação, objetivo final da Colnfo de maneira cíclica. Sendo assim, o processo de construção de conhecimento eficaz de maneira competente é cíclico e ocorre ao longo da vida da sociedade. Portanto, sugere-se que a busca, avaliação e o uso da informação são etapas que contribuem com a valorização da comunidade LGBTQ.

Ao conhecer o modo de vida, as pessoas podem aprender a respeitar às 
escolhas das minorias. A construção conhecimento é fundamental para a redução do estigma em relação aos LGBTQ, pois permite que os indivíduos compreendam seu contexto em vários aspectos. Consequentemente, há a redução do preconceito e de homofobia contra a comunidade.

\section{CONSIDERAÇÕES FINAIS}

A Colnfo pode contribuir para que a sociedade desenvolva o respeito à comunidade LGBTQ. Os padrões e indicadores desta competência são norteadores das ações dos indivíduos em sociedade. $\mathrm{O}$ acesso, avaliação e uso da informação possibilitam que as pessoas construam conhecimento sobre 0 contexto desse grupo e com isso, desmitifique os preconceitos enraizados na sociedade.

Os indivíduos podem usar a informação para aprender mais sobre o modo de vida dos LGBTQ, a fim de reduzir o preconceito. Como resultado há o desenvolvimento do respeito à diversidade em sociedade, reduzindo a criminalidade contra as pessoas diferentes do padrão conservador.

A literatura da Ciência da Informação ainda tem tratado do tema da Colnfo e dos LGBTQ de maneira tímida, já que poucos artigos foram encontrados nas bases de dados pesquisadas. Os artigos recuperados na RSL foram também publicados por áreas correlatas à Ciência da Informação. Essas áreas do conhecimento podem servir de parceiros interdisciplinares. Desse modo, sugerese o desenvolvimento de pesquisa científica a respeito da temática a fim de incluí-los em suas pesquisas. Como desenvolvimento a pesquisas futuras sugere-se investigar de que maneira os membros de comunidades LGBTQ experienciam a Colnfo em suas práticas, bem como aplicá-la em vários cursos, valorizando os direitos humanos e a cidadania.

\section{REFERÊNCIAS}

ALLAN, K.; BURRIDGE, K. Forbidden Words: taboo and the censoring of language. Cambridge: University Press, 2006. 
BARBERO, G. H. A psicanálise e os modernos movimentos de "afirmação homossexual". Psicologia: ciência e profissão, v. 19, n. 2 Brasília, 1999.

BEAL, A. Gestão estratégica da informação. São Paulo: Atlas, 2004.

BELLUZZO, R. C. B. Construção de mapas: desenvolvendo competências em informação e comunicação. Bauru: Autores Brasileiros, 2007.

BELLUZZO, R. C. B.; FERES, G. G. Competência em informação, redes de conhecimento e as metas educativas para 2021: reflexões e inter-relações. In: BELLUZZO, R. C. B; FERES, G. G.; VALENTIM, M. L. P. (Orgs.). Redes de conhecimento e competência em informação: interfaces da gestão, mediação e uso da informação/organização. Rio de Janeiro: Interciência, 2015. 414 p. p. 1-35.

BUNDY, A. Australian and New Zealand Information Literacy Framework: principles, standards and practice. 2004. Disponível em: http://archive.caul.edu.au/info-literacy/InfoLiteracyFramework.pdf. Acesso em: 18 jun. 2018.

DANIEL, M.; BAUDRY, A. Os homossexuais. Rio de Janeiro: Editora Arte Nova, 1977.

DRAKE, A. A.; BIELEFIELD, A. Equitable access: Information seeking behavior, information needs, and necessary library accommodations for transgender patrons. Library \& Information Science Research, v. 39, n. 3, p. 160-168, 2017.

DUDZIAK, E. A. Information literacy: princípios, filosofia e prática.

Ciência da Informação, Brasília, v. 32, n. 1, p. 23-35, jan./abr. 2003.

ELIASON, M. J.; ROBINSON, P.; BALSAM, K. Development of an LGB-specific health literacy scale. Health Communication, v. 33, n. 12, p. 1531-1538, 2018. DOI: 10.1080/10410236.2017.1372052.

FERNÁNDEZ-MARTOS, J. M.; VIDAL, M. Esclarecimentos fundamentais: nome, definição, tipos e normalidade. In: VIDAL, M.; GAFO, J.; FERNÁNDEZMARTOS, J. M.; LASSO, P.; RUIZ, G.; HIGUERA, G. Homossexualidade: ciência e consciência. São Paulo: Edições Loyola, 1985. p. 7-15.

FOUCAULT, M. História da sexualidade 1: a vontade de saber. Rio de Janeiro: Graal, 1999.

GOHN, M. da G. Abordagens teóricas no estudo dos movimentos sociais na América Latina. Caderno CRH, Salvador, v. 21, n. 54, p. 439-455, set./dez. 2008. Disponível em: http://www.scielo.br/scielo.php?pid=S010349792008000300003\&script=sci_abstract\&tIng=pt. Acesso em: 02 ago. 2018. 
HAMMER, J. D. Coming-Out: Gay Males' Information Seeking. School Libraries Worldwide, v .9, n.2, p. 73-89, 2003.

HART, G.; MFAZO, N. Places for all? Cape Town's public library services to gays and lesbians. South African Journal of Libraries \& Information Science, v. 76, n. 2, p. 81-90, 2010.

HOLTZMAN, L. Mining the invisible: teaching and learning media and diversity. American Behavioral Scientist, v. 48, n. 1, p. 108-118, 2004. Disponível em: http://journals.sagepub.com.ez87.periodicos.capes.gov.br/doi/pdf/10.1177/0002 764204267256. Acesso em: 26 jul. 2018.

JUHASZ, A.; MA, M. Y. S. Lesbian Archives. Journal of Lesbian and Gay Studies, v. 17, n. 4, 2011. Disponível em: https://read.dukeupress.edu/glq/article-abstract/17/4/619/34787/LesbianArchives. Acesso em: 07 dez. 2018.

LAU, J. Diretrizes sobre desenvolvimento de habilidades de informação para a aprendizagem permanente. The Haague: IFLA, 2007. Disponível em: https://www.ifla.org/files/assets/information-literacy/publications/ifla-guidelinespt.pdf. Acesso em: 08 jul. 2018.

LEE, R. H. Reading and aids literacy in Allen Barnett's short fiction. Literature and Medicine, v. 31, n. 1, p. 142-173, 2013. Disponível em: http://muse-jhuedu.ez87.periodicos.capes.gov.br/article/523378. Acesso em: 27 jul. 2018.

MEHRA, B.; LEMIEUX III, P. A.; BURWELL, C.; HIXSON, T.; PARTEE II, R. P.; STOPHEL, K.; WOOD, N. E. Expanding LIS education in the US department of state's diplomacy lab program: GIS and LGBTI advocacy in Africa and Latin America. Journal of Education for Library and Information Science, v. 59, n. 3, p. 4-16, 2018.

OTTONICAR, S. L. C. Análise teórico-descritiva da competência em informação de gestores como fator de competitividade das indústrias de eletroeletrônicos da cidade de Garça/SP. 2016. 271 f. Dissertação (Mestrado em Ciência da Informação) - Universidade Estadual Paulista, Faculdade de Filosofia e Ciências, Marília, 2016.

OTTONICAR, S. L. C., FERES, G. G. Information Literacy in Brazil. In: KURBANOGLU, S., ŠPIRANEC, S.; GRASSIAN, E.; MIZRACHI, D.; CATTS, R. (Eds.) Information Literacy. Lifelong Learning and Digital Citizenship in the 21st Century. ECIL 2014. Communications in Computer and Information Science, v. 492. Springer, Cham, 2014.

PINHO, F. A. Aspectos éticos em representação do conhecimento em temáticas relativas à homossexualidade masculina: uma análise da 
precisão em linguagens de indexação brasileiras. 2010. $149 \mathrm{f}$. Tese (Doutorado em Ciência da Informação) - Universidade Estadual Paulista, Faculdade de Filosofia e Ciências, Marília, 2010. Disponível em:

https://www.marilia.unesp.br/Home/Pos-

Graduacao/Cienciadalnformacao/Dissertacoes/pinho_fa_do_mar.pdf. Acesso em: 22. ago. 2018

REIS, M. K. S.; CARVALHO, M. M.; MUNIZ, E. M. de P. T. "Information Literacy" ou Competência em informação como elemento promotor do desenvolvimento do capital intelectual. In: CONGRESSO BRASILEIRO DE BIBLIOTECONOMIA, DOCUMENTAÇÃO E CIÊNCIA DA INFORMAÇÃO, 24., 2011. Anais... Alagoas: Centro Cultural e de Exposições Ruth Cardoso, 2011. Disponível em: https://www.passeidireto.com/arquivo/32511805/informationliteracy-ou-competncia-em-informaocomo-. Acesso em: 15 jul. 2018.

RIGHETTO, G. G. Competência em informação de minorias sociais: pessoas transexuais da região de Florianópolis, Santa Catarina. 2018. 353 f. Dissertação (Mestrado em Ciência da Informação) - Universidade Federal de Santa Catarina, Florianópolis, 2018. Disponível em: https://repositorio.ufsc.br/bitstream/handle/123456789/186804/PCIN0174D.pdf?sequence=-1\&isAllowed=y. Acesso em: 15 jul. 2018.

ROTHBAUER, P. M. "People aren't afraid anymore, but it's hard to find books": reading practices that inform the personal and social identities of self-identified lesbian and queer young women. In: PROCEEDINGS OF THE ANNUAL CONFERENCE CAIS I ACTES DU CONGRĖS ANNUEL DE L'ACSI, 2004.

SANTOS, R. N. R. dos; TARGINO, M. das G.; FREIRE, I. M. A temática diversidade sexual na Ciência da Informação: a perspectiva da responsabilidade social. Rebecin: Revista Brasileira de Educação em Ciência da Informação, v. 4, n. 1, p. 114-135, jan./jun. 2017. Disponível em: http://abecin.org.br/portalderevistas/index.php/rebecin/article/view/57/pdf. Acesso em: 24 jul. 2018.

SERAFIM, L. A.; FREIRE, G. H. de A. Ação de responsabilidade social para competências em informação. Perspectivas em Ciência da Informação, Belo Horizonte, v. 17, n. 3, p. 155-173, jul./set. 2012. Disponível em:

http://www.scielo.br/pdf/pci/v17n3/a11v17n3.pdf. Acesso em: 17 jul. 2018.

SILVA, R. C.; OTTONICAR, S. L. C.; YAFUSHI, C. P. A competência em informação e midiática voltada à cidadania: o uso da informação governamental para a participação na democracia. Revista Digital de Biblioteconomia e de Ciência da Informação, v. 15, n. 3, p. 604-628, set./dez. 2017.

SILVA, A. L.; SANTOS, S. M. M. "O sol não nasce para todos": uma análise do direito à cidade para os segmentos LGBT. SER Social, Brasília, v. 17, n. 37, p. 498-516, jun./dez. 2015. 
SHANNON, B. Comprehensive for who? Neoliberal directives in Australian 'comprehensive' sexuality education and the erasure of GLBTIQ identity. Sex

Education, v. 16, n. 6, p. 573-585, 2016. DOI:

10.1080/14681811.2016.1141090

SPENCER, C. Homossexualidade: uma história. Rio de Janeiro: Editora Record, 1996.

WOODLAND, R. "I plan to be a 10": Online literacy and lesbian, gay, bisexual, and transgender students. Computers and composition, v. 16, n. 1, p. 73-87, 1999. Disponível em: https://ac-els-

cdn.ez87.periodicos.capes.gov.br/S8755461599800061/1-s2.0-

S8755461599800061-main. pdf? tid=0218a77a-d7ae-45bd-b9baa144a3cf9d99\&acdnat=1532741490_098f8983f982da99a1f2396e291136ce. Acesso em: 27 jul. 2018.

YOUNG, I.; FLOWERS, P.; McDAID, L. M. Key factors in the acceptability of treatment as prevention (TasP) in Scotland: a qualitative study with communities affected by HIV. Sexual Transmitted Infections, v. 91, n. 4, p. 269-74, 2015.

\title{
INFORMATION LITERACY IN THE CONTEXT OF LGBT COMMUNITY: A SURVEY OF NATIONAL AND INTERNATIONAL PUBLICATIONS
}

\begin{abstract}
Introduction: The LGBT Community has been facing difficulties in society because of some people's prejudice. The law of many countries and public policy have focused on these groups, so they can be included in society. The purpose is to guarantee human rights and respect minority to improve people's life quality. Objectives: This paper aims to discuss how information literacy can contribute to the respect of LGBTQ community. Furthermore, it also aims to demonstrate how Information Science theory has studied the theme to include the LGBTQ community in research. Methodology: It involves a systematic literature review about information literacy and LGBTQ in Information Science field. Results: The theme is not very common in Information Science in both national and international contexts. Furthermore, the paper introduced a model to show how information literacy can help to LGBTQ community. That model can be used in many contexts to reduce prejudice against minorities. Conclusions: There is a need for more deep research about the theme. The effective use of information contributes to understand the LGBTQ context and respect their life style.
\end{abstract}

Descriptors: Information Literacy. Interdisciplinarity. LGBTQ community. Respect for diversity. Systematic Literature Review. 


\title{
ALFABETIZACIÓN INFORMACIONAL EN EL ÁMBITO DE LA COMUNIDAD LGBTQ: UN LEVANTAMIENTO DE PUBLICACIONES CIENTÍFICAS NACIONALES E INTERNACIONALES
}

\begin{abstract}
RESUMEN
Introducción: La comunidad de Lesbianas, Gays, Bisexuales, Transexuales y Queers (LGBTQ) ha enfrentado dificultades en la sociedad contemporánea debido al preconcepto de algunos individuos. Actualmente, las leyes de diversos países, así como las políticas públicas, han sido direccionadas a estos grupos, para incluirlos en sociedad. El foco es garantizar el derecho de los seres humanos y el respeto a las minorías, con el objetivo de mejorar la calidad de vida de esas personas. Delante de estas reflexiones, el problema de investigación buscó ponderar las maneras en que la alfabetización informacional puede contribuir a que la sociedad desarrolle respeto por la comunidad LGBTQ. Objetivos: Demostrar los modos por los cuales la literatura de la Ciencia de la Información ha tratado la temática, a fin de incluir a la comunidad LGBTQ en sus investigaciones. Metodología: La metodología utiliza revisión sistemática de literatura en el área de la Ciencia de la Información sobre la competencia en información y el movimiento LGBTQ, a fin de identificar cómo el tema viene siendo tratado por el área. Resultados: Se percibió que el tema enfocado es tratado de manera tímida por el área y que fue desarrollado un modelo de respeto a la comunidad LGBTQ mediante esta competencia, con el fin de ser aplicado en diversos contextos buscando reducir el preconcepto con sus miembros. Conclusiones: Pudo observarse la necesidad de estudios más profundos sobre la temática. El uso de información eficaz contribuye para la compresión del contexto de la comunidad LGBTQ y el respeto por sus formas de vida.
\end{abstract}

Descriptores: Alfabetización Informacional. Comunidad LGBT. Respeto a la diversidad. Interdisciplinariedad. Revisión Sistemática de la Literatura. 